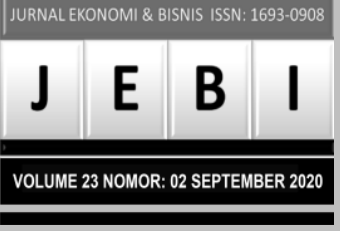

\title{
FAKTOR-FAKTOR YANG MEMENGARUHI KEMAUAN MEMBAYAR PAJAK WAJIB PAJAK ORANG PRIBADI YANG MELAKUKAN PEKERJAAN BEBAS (STUDI KASUS PADA KPP PRATAMA KOTA PEKALONGAN)
}

\author{
Dian Prihatiningsih \\ Fakultas Ekonomika Universitas Pekalongan \\ e-mail: dian.unikal@gmail.com
}

\begin{abstract}
This study aims to analyze the factors that affect the willingness to pay taxes on taxpayers of individuals who perform free work in the office of KPP Pratama Pekalongan. The variables in this study are taxpayer willingness as dependent variable knowledge of taxation regulation, understanding of tax regulation, good perception on tax system and level of trust to government system and law as independent variable. The population in this study were free workers registered in KPP pratama stem. The sample used in this research is as many as 63 respondents are free workers registered in KPP pratama stem. Meanwhile, to answer the hypothesis in this research is done classical assumption test and multiple linear regression. The result of the research shows that variable knowledge of tax regulations, understanding of tax regulations, a good perception of the effectiveness of the taxation system has a significant effect on willingness to pay taxes but for the level of trust in the government and the legal system has no significant effect on willingness to pay taxes.
\end{abstract}

Keywords: knowledge of tax regulations, understanding of tax laws, good perceptions of the effectiveness of the tax system and the degree of confidence in government and legal systems.

\section{Pendahuluan}

Pajak merupakan penerimaan negara terbesar. Kurang lebih 2/3 penerimaan negara saat ini bersumber dari pajak. Dominasi pajak sebagai sumber penerimaan merupakan satu hal yang sangat wajar, terlebih ketika sumber daya alam, khususnya minyak bumi tidak bisa lagi diandalkan. Penerimaan dari sumber daya alam mempunyai umur yang relatif terbatas. Suatu saat akan habis dan tidak bisa diperbarui. Hal ini berbeda dengan pajak: sumber penerimaan ini mempunyai umur tidak terbatas, terlebih dengan semakin bertambahnya jumlah penduduk. Kemauan wajib pajak dalam membayar kewajiban perpajakannya merupakan hal penting dalam penarikan pajak tersebut. Penyebab kurangnya pemungutan pajak tersebut tidak langsung dinikmati oleh para wajib pajak. Adapun kemauan membayar pajak dipengaruhi oleh beberapa faktor, yaitu kesadaran akan membayar pajak, pengetahuan tentang peraturan perpajakan, pemahaman tentang peraturan perpajakan serta tingkat kepercayaan terhadap sistem pemerintahan dan hukum.

Pengetahuan tentang peraturan perpajakan sangat penting untuk menumbuhkan kemauan membayar pajak. Pengetahuan didapat ketika wajib pajak usaha dalam mendewasakan diri melalui pengajaran dan pelatihan akan perpajakan isi tentang peraturan perpajakan. Pemerintah Indonesia memilih penerapkan self assessment system dalam rangka pelaksanaan pemungutan 
pajak (Nugroho, 2016). Pada self assessment system sendiri wajib pajak diwajibkan dan diberikan kepercayaan untuk menghitung, menyetorkan dan melaporkan pajaknya sendiri.

Selain itu pemahaman akan tentang perpajakan juga sangat penting untuk menumbuhkan kemauan membayar pajak wajib pajak sendiri. Pemahaman Wajib Pajak terhadap peraturan perpajakan adalah cara Wajib Pajak dalam memahami peraturan perpajakan yang telah ada (Hardiningsih dan Yulianawati, 2011). Bagaimana wajib pajak paham kewajibannya sebagai wajib pajak, paham akan sanksi yang diterima wajib pajak apabila wajib pajak tidak melaporkan bahkan tidak melaporkan dengan benar dan juga paham akan peraturan perpajakan melalui sosialisasi maupun training yang pernah diikuti oleh wajib pajak. Semakin wajib pajak paham akan peraturan perpajakan semakin baik pula wajib pajak paham terhadap sanksi yang akan diterima seperti sanksi administrasi maupun pidana apabila wajib pajak melalaikan kewajiban membayar pajaknya.

Menurut Nugroho dan Zulaika (2012), menyatakan bahwa persepsi atas efektifitas sistem perpajakan dapat mempengaruhi kesadaran wajib pajak dalam memenuhi kewajiban perpajakan. Untuk meningkatkan kesadaran wajib pajak dalam membayar pajak, Direktorat Jendral Pajak membuat suatu sistem pendukung yang diharapkan dapat memudahkan wajib pajak dalam membayar dan melaporkan kewajiban pajaknya yaitu dengan adanya e-filling, e-SPT, e-NPWP, drop box dan e-banking (Nugroho, 2016).

Menurut Handayani (2012), kepercayaan dalam sistem pemerintahan dan hukum yang berlaku turut mendorong kemauan wajib pajak untuk membayar pajaknya ketika wajib pajak memiliki kepercayaan yang tinggi kepada sistem pemerintahan dan hukum yang tegas dalam melaksanakan semua aturan-aturan yang berlaku. Misalnya ketika wajib pajak terlambat membayar atau melaporkan pemerintah dengan berlandaskan hukum yang telah dibuat bertindak tegas untuk mengenakan denda kepada wajib pajak tersebut. Hal ini mungkin akan meningkatkan kemauan wajib pajak untuk membayar pajaknya. Tanpa harus menunda pembayaran pajaknya.

Dari faktor diatas yang menyebabkan kurangnya wajib pajak untuk membayar pajak, ada beberapa faktor lainnya seperti sanksi pajak, norma moral, kualitas layanan terhadap wajib pajak, dan layanan fiskus terhadap wajib pajak yang menyebabkan juga wajib pajak tidak mau untuk membayar pajak.

Tujuan yang ingin dicapai oleh peneliti dengan melakukan penelitian ini adalah untuk mengetahui dan membuktikan :

1. Pengaruh Pengetahuan Peraturan Pajak terhadap kemauan membayar pajak

2. Pengaruh Pemahaman Peraturan Pajak terhadap kemauan membayar pajak

3. Pengaruh Persepsi Sistem Pajak terhadap kemauan membayar pajak

4. Pengaruh Tingkat Kepercayaan Hukum terhadap kemauan membayar pajak.

\section{Materi dan Metode Penelitian}

\section{Theory of Perceived Behavior (TPB)}

Theory of Perceived Behavior (TPB) menyatakan bahwa selain sikap terhadap tingkah laku dan norma-norma subjektif, individu juga mempertimbangkan control tingkah laku yang di persepsikannya yaitu kemampuan mereka untuk melakukan tindakan tersebut (Ajzen dalam Nugroho, 2012).

Pengetahuan perpajakan dapat dicari dari berbagai banyak sumber, dari edukasi brevet pajak, media cetak, atau bahkan dari jejaring media sosial pun bersedia berbagai info mengenai perpajakan. Dengan adanya pengetahuan mengenai perpajakan, akan mendukung atau mempengaruhi kemauan dalam membayar pajak (Sukma, 2015).

Pemahaman wajib pajak terhadap peraturan perpajakan adalah cara wajib pajak dalam memahami peraturan perpajakan yang telah ada (Hardiningsih dan Yulianawati, 2011).

Dalam penelitian Handayani, dkk (2012) menyatakan selama ini banyak wajib pajak yang telah terdaftar sebagai wajib pajak, dan telah memiliki NPWP belum mau melaksanakan kewajiban pajak dengan baik. Hal ini disebabkan oleh asas perpajakan bahwa hasil pemungutan pajak tidak langsung dinikmati oleh pembayar pajak (Hardiningsih dan Yulianawati, 2011). Persepsi dapat dinyatakan sebagai suatu proses pengorganisasian, pengintepretasian terhadap stimulus oleh organisasi atau individu sehingga merupakan suatu yang berarti dan merupakan aktivitas integritas dalam diri individu.

Menurut Handayani (2012) menyatakan kepercayaan dalam sistem pemerintahan dan hukum yang berlaku turut mendorong kemauan membayar pajak untuk membayar pajaknya ketika 
wajib pajak memiliki kepercayaan yang tinggi kepada sistem pemerintahan dan hukum yang tegas dalam melaksanakan semua aturan-aturan yang berlaku. Misalnya ketika wajib pajak terlambat membayar atau melaporkan pemerintah dengan berlandasan hukum yang telah dibuat bertindak tegas untuk mengenakan denda kepada wajib pajak tersebut.

\section{Jenis dan Obyek Penelitian}

Penelitian ini merupakan penelitian kausal, yaitu penelitian dimana informasi dikumpulkan oleh responden dengan menggunakan kuesioner dengan menggunakan suatu teknik pengumpulan informasi yang dilakukan dengan cara menyusun daftar pertanyaan yang diajukan kepada responden (Masri dan Sofian dalam Handayani, dkk, 2012). Obyek penelitian ini dilakukan di Kantor Pajak Pratama Pekalongan.

\section{Sampel Penelitian dan Teknik Pengumpulan data}

Sampel dalam penelitian ini adalah pekerja bebas yang terdaftar di kantor pelayanan pratama Kota Pekalongan dalam hal tenaga ahli dan pekerja lainnya. Pengambilan sampel menggunakan metode purposive sampling. Jenis data dalam penelitian ini adalah data primer dan dilakukan dengan metode survei dengan membagikan kuesioner sebanyak 70 dan yang kembali hanya 63 kuesioner.

Pengukuran variabel ini menggunakan instrument kuesioner, dan diukur dengan skala likert's lima point yaitu pengukuran sikap responden dengan menyatakan setuju atau tidak setuju. Dimana setiap jawaban akan diberikan point.

Analisis data yang digunakan yaitu regresi linier berganda dengan model persamaan seperti berikut:

$$
\begin{aligned}
& Y=\alpha+\beta 1 X 1+\beta 2 X 2+\beta 3 X 3+\beta 4 X 4+\text { e Keterangan: } \\
& \mathrm{Y} \quad=\text { Kemauan Membayar pajak } \\
& \text { a } \quad=\text { Konstanta } \\
& \text { b1, b2, b3 = Koefisien Regresi } \\
& \mathrm{X} 1=\text { Pengetahuan Peraturan Pajak } \\
& \text { X2 }=\text { Pemahaman Peraturan Pajak } \\
& \text { X3 }=\text { Persepsi Sistem Pajak } \\
& \text { X4 = Tingkat Kepercayaan Hukum } \\
& \mathrm{E}=\text { error }
\end{aligned}
$$

Uji koefesien determinasi digunakan untuk mengetahui seberapa besar varian dari variabel dependen dapat dijelaskan oleh variabel independen. R 2 yang digunakan dalam penelitian ini adalah R 2 yang mempertimbangkan jumlah variabel independen dalam suatu model atau disebut R 2 yang telah disesuaikan (Adjusted-R 2).

\section{Hasil Penelitian dan Pembahasan}

\section{Regresi Linier Berganda}

Pengujian hipotesis dalam penelitian ini menggunakan analisis regresi linier berganda. Uji ini digunakan untuk mengetahui apakah variabel independen (Pengetahuan Peraturan Pajak, Pemahaman Peraturan Pajak, Persepsi Sistem Pajak, Tingkat Kepercayaan Hukum) berpengaruh signifikan terhadap variabel dependen Kemauan Membayar Pajak.

Berdasarkan tabel 1 tingkat signifikan pada Pengetahuan Peraturan Pajak sebesar 0,000 lebih kecil dari $(\alpha)=0,05$ maka $\mathrm{H} 1$ diterima, tingkat signifikan pada Pemahaman Peraturan Pajak sebesar 0,029 lebih kecil dari $(\alpha)=0,05$ maka $\mathrm{H} 2$ diterima. tingkat signifikan pada Persepsi Sistem Pajak sebesar 0,000 lebih kecil dari $(\alpha)=0,05$ maka H3 diterima. tingkat signifikan pada Tingkat Kepercayaan Hukum sebesar 0,420 lebih besar dari $(\alpha)=0,05$ maka $\mathrm{H} 4$ ditolak.

Tabel 1

Hasil Analisis Regresi Berganda

Coefficients $^{\text {a }}$

\begin{tabular}{llrrrrrr}
\hline & & \multicolumn{2}{c}{$\begin{array}{c}\text { Unstandardized } \\
\text { Coefficients }\end{array}$} & \multicolumn{2}{c}{$\begin{array}{c}\text { Standardized } \\
\text { Coefficients }\end{array}$} & & \\
\cline { 3 - 6 } Model & & \multicolumn{1}{c}{ B } & Std. Error & Beta & t & Sig. \\
\hline \multirow{2}{*}{1} & (Constant) & 2.702 & 1.267 & & 2.132 & .037 \\
& Total_PENGETAHUAN & .526 & .074 & .565 & 7.138 & .000 \\
& Total_PEMAHAMAN & -.265 & .119 & -.270 & -2.238 & .029 \\
& Total_PERSEPSI & .731 & .149 & .782 & 4.902 & .000 \\
& Total_KEPERCAYAAN_HUKUM & -.123 & .151 & -.119 & -.812 & .420 \\
\hline
\end{tabular}

a. Dependent Variable: Total_KEMAUAN_MEMBAYAR_PAJAK 
Tabel 2

Adjusted-R 2

\begin{tabular}{lccrr}
\hline & & & \multicolumn{2}{c}{$\begin{array}{c}\text { Std. Error of the } \\
\text { Model }\end{array}$} \\
\hline 1 & R & R Square & Adjusted R Square & Estimate \\
\hline a. & Predictors: (Constant), Total_KEPERCAYAAN_HUKUM, & .92858 \\
& Total_PENGETAHUAN, Total_PEMAHAMAN, Total_PERSEPSI
\end{tabular}

Dari tabel 1 maka dapat ditarik persamaan regresi sebagai berikut :

$Y=\alpha+\beta 1 X 1+\beta 2 X 2+\beta 3 X 3+\beta 4 X 4+e$

$Y=2,702+0,526 \times 1-0,265 X 2+0,731 X 3-0,123 \times 4+e$

Dari persamaan tersebut dapat dijelaskan bahwa variabel pengetahuan peraturan pajak, pemahaman peraturan pajak, persepsi sistem pajak, tingkat kepercayaan hukum berpengaruh positif terhadap kemauan membayar pajak.

1. Variabel Pengetahuan Peraturan Pajak mempunyai pengaruh positif 0,526 dengan signifikansinya sebesar 0,000 (signifikan) terhadap kemauan membayar pajak, artinya pengetahuan yang cukup tentang peraturan pajak bagi para wajib pajak diperlukan agar mereka memiliki kompetensi dan pengetahuan akan peraturan pajak sehingga menimbulkan kemauan akan membayar pajak. Jadi semakin meningkat pengetahuan peraturan pajak maka semakin baik dan meningkatkan kesadaran para wajib pajak untuk membayar pajak kepada negara. sehingga pengetahuan peraturan pajak berpengaruh terhadap kesadaran dan kemauan membayar pajak kepada negara.

2. Variabel Pemahaman Peraturan Pajak mempunyai pengaruh negatif -0,265 dengan signifikansinya sebesar 0,029 (signifikan) terhadap kemauan membayar pajak, artinya Pemahaman yang rendah tentang peraturan pajak bagi para wajib pajak maka jika semakin banyak pemahaman yang perlu di pahami oleh wajib pajak akan menyebabkan tingkat kemauan membayar pajak semakin rendah.

3. Variabel persepsi yang baik atas efektifitas sistem pajak mempunyai pengaruh positif 0,731 dengan signifikansinya sebesar 0,000 (signifikan) terhadap kemauan membayar pajak, artinya ketika persepsi atas efektifitas sistem perpajakan meningkat maka semakin meningkatnya pengaruh dorongan bagi wajib pajak untuk membayar pajak.

4. Variabel Tingkat Kepercayaan Hukum mempunyai pengaruh negatif $-0,123$ dengan signifikansinya sebesar $0,420 \quad$ (tidak signifikan) terhadap kemauan membayar pajak, artinya tingkat kepercayaan pada hukum yang rendah maka jika semakin banyak hukum tentang pajak berlaku mengenai pembayaran pajak tidak akan mempengaruhi tingkat kemauan membayar pajak atau kemauan membayar pajak rendah.

Koefisien Determinasi (R2)

Koefisien determinasi menunjukkan variasi variabel dependen yang dapat dijelaskan oleh variasi variabel independen. Pada tabel 2 diketahui nilai koefisien determinasi adalah 0,807 , yang artinya hubungan antara variabel bebas (pengetahuan peraturan pajak, pemahaman peraturan pajak, persepsi sistem pajak, tingkat kepercayaan hukum) dengan variabel terikat (kemampuan membayar pajak) berada pada tingkat hubungan lemah, artinya pengetahuan peraturan pajak, pemahaman peraturan pajak, persepsi sistem pajak, tingkat kepercayaan hukum signifikan terhadap kemauan membayar pajak.

Berdasarkan hasil perhitungan koefisien determinasi, dapat diketahui bahwa pengetahuan peraturan pajak, pemahaman peraturan pajak, persepsi sistem pajak, tingkat kepercayaan hukum memiliki pengaruh sebesar 80,7\% terhadap kemauan membayar pajak dan sisanya 19,3\% dipengaruhi oleh faktor-faktor lain diluar variabel yang diteliti.

\section{SIMPULAN}

Berdasarkan hasil analisis data dan pembahasan yang telah dilakukan, maka dapat diambil kesimpulan sebagai berikut:

1. Pengetahuan tentang peraturan perpajakan berpengaruh signifikan terhadap kemauan membayar pajak. Pengetahuan yang cukup tentang peraturan pajak bagi para wajib pajak diperlukan agar mereka memiliki kompetensi dan pengetahuan akan peraturan pajak sehingga menimbulkan kemauan akan 
membayar pajak. Jadi semakin meningkat pengetahuan peraturan pajak maka semakin baik dan meningkatkan kesadaran para wajib pajak untuk membayar pajak kepada Negara sehingga pengetahuan peraturan pajak berpengaruh terhadap kesadaran dan kemauan membayar pajak kepada negara.

2. Pemahaman tentang peraturan perpajakan berpengaruh negative signifikan terhadap kemauan membayar pajak. Hal ini karena pemahaman yang rendah tentang peraturan pajak bagi para wajib pajak maka jika semakin tinggi pemahaman yang perlu di pahami oleh wajib pajak akan menyebabkan tingkat kemauan membayar pajak semakin rendah.

3. Persepsi yang baik atas efektifitas sistem perpajakan berpengaruh terhadap kemauan membayar pajak. Ketika persepsi atas efektifitas sistem perpajakan meningkat maka akan memberikan pengaruh meningkatnya dorongan bagi wajib pajak untuk membayar pajak.

4. Tingkat kepercayaan hukum berpengaruh negative tidak signifikan terhadap kemauan membayar pajak. Semakin rendah tingkat kepercayaan wajib pajak terhadap sistem pemerintahan dan hukum, maka kemauan membayar pajak pun semakin tinggi.

Penelitian ini mempunyai keterbatasan sehingga saran untuk penelitian berikutnya:

1. Hendaknya sampel dan daerah penelitian lebih diperluas lagi dapat digeneralisasikan untuk seluruh wilayah di Indonesia selain itu menambah jumlah variabel, karena pada dasarnya masih banyak faktor-faktor lain yang kemungkinan berpengaruh terhadap kemauan membayar pajak.

2. Indikator pemahaman dan kepercayaan hukum kemungkinan kurang sesuai sehingga hasilnya menunjukkan negatif.

\section{DAFTAR PUSTAKa}

Ghozali, Imam. 2016. Aplikasi Analisis Multivariate dengan Program SPSS. Semarang: Badan Penerbitan. Universitas Diponegoro.
Handayani, Sapta Wuri., Agus Faturokhman dan Umi Pratiwi. 2012. "Faktor-faktor yang mempengaruhi Kemauan Membayar Pajak Wajib Pajak Orang Pribadi yang Melakukan Pekerjaan Bebas". Simposium Nasional Akuntansi XV Universitas Jenderal Soedirman Purwokerto.

Hardiningsih dan Yulianawati, 2011. "Faktor-Faktor Yang Mempengaruhi Kemauan Membayar Pajak (The Factors That Influence The Willingness To Pay The Tax)". Dinamika Keuangan dan Perbankan, Nov.2011. Hal: $126-142$

Nugroho, E. 2016. "Faktor-Faktor yang Mempengaruhi Kemauan Membayar Pajak Wajib Pajak Orang Pribadi yang Melakukan Pekerjaan Bebas di KPP Pratama Yogyakarta". Jurnal Fakultas Ekonomi. Universitas Negeri Yogyakarta

Nugroho, R. A., dan Zulaikha, 2012. "Faktor-Faktor yang Mempengaruhi Kemauan Untuk Membayar Pajak dengan Kesadaran Membayar Pajak Sebagai Variabel Intervening (Studi Kasus Wajib Pajak Orang Pribadi yang Melakukan Pekerjaan Bebas yang Terdaftar di KPP Pratama Semarang)". Diponegoro Journal of Accounting. Volume I (28): 1-11

Sukma. 2015. Analisis Faktor-Faktor Yang Mempengaruhi Kemauan Membayar Pajak (Studi Pada WPOP yang Memiliki Kegiatan Usaha di Semarang). Skripsi dipublikasikan. Fakultas Ekonomika dan Bisnis. Universitas Diponegoro. Semarang. 33-60.

https://duniapengetahuan2627.blogspot.co.id/201 3/02/pengertian-self-assessment system.html. Diakses tanggal 20 Januari 2018 